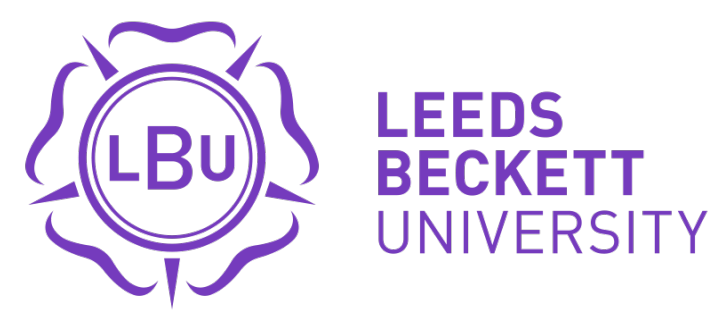

Citation:

Fletcher, M and Glew, D and Hardy, ALR and Gorse, C (2020) A modified approach to metabolic rate determination for thermal comfort prediction during high metabolic rate activities. Building and Environment, 185. ISSN 0007-3628 DOI: https://doi.org/10.1016/j.buildenv.2020.107302

Link to Leeds Beckett Repository record:

https://eprints.leedsbeckett.ac.uk/id/eprint/7068/

Document Version:

Article (Accepted Version)

Creative Commons: Attribution-Noncommercial-No Derivative Works 4.0

The aim of the Leeds Beckett Repository is to provide open access to our research, as required by funder policies and permitted by publishers and copyright law.

The Leeds Beckett repository holds a wide range of publications, each of which has been checked for copyright and the relevant embargo period has been applied by the Research Services team.

We operate on a standard take-down policy. If you are the author or publisher of an output and you would like it removed from the repository, please contact us and we will investigate on a case-by-case basis.

Each thesis in the repository has been cleared where necessary by the author for third party copyright. If you would like a thesis to be removed from the repository or believe there is an issue with copyright, please contact us on openaccess@leedsbeckett.ac.uk and we will investigate on a case-by-case basis. 


\title{
A modified approach to metabolic rate determination for thermal comfort prediction during high metabolic rate activities
}

\author{
M. J. Fletcher ${ }^{1}$, D. W. Glew ${ }^{1}$, A. Hardy ${ }^{1}$, C. Gorse ${ }^{1}$ \\ ${ }^{1}$ Centre for the Built Environment, Leeds Sustainability Institute, Leeds Beckett University, NT106 \\ Northern Terrace, Woodhouse Lane, Leeds, LS2 8AG, UK \\ Corresponding Author: M.F.Fletcher@Leedsbeckett.ac.uk, +44 1138129397 \\ Additional details: D.W.Glew@Leedsbeckett.ac.uk; C.Gorse@Leedsbeckett.ac.uk; \\ A.L.Hardy@Leedsbeckett.ac.uk
}

\begin{abstract}
Environmental conditions in buildings are linked to the physical and mental wellbeing of occupants. Thus, it follows that the internal environment affects human performance and user experience during sport and activity. There are several indices that are used to evaluate occupant thermal comfort, the Predicted Mean Vote (PMV) index being the metric most commonly used. PMV is designed to evaluate comfort for sedentary occupants with low metabolic rates; however, PMV has also been used to evaluate comfort for individuals engaged in high metabolic rate activities, such as those common in sport facilities.
\end{abstract}

This paper investigates the implication of using PMV to evaluate thermal comfort in sport facilities using empirical data recorded over 24 months in a multi-purpose sports hall in the North of England. Data are used to develop and propose methodological modifications to improve the standard PMV model prediction to account for occupants having higher metabolic rates.

The paper evaluates the use of metabolic rate data from different sources including the Compendium of Physical Activities and quantifies the impact that the metabolic weighting approach has on predicted comfort. Finally, a novel method is proposed to modify PMV for use where occupants have high metabolic rates.

Despite the improvements made, the findings suggest that even a modified PMV may not be able to accurately evaluate the thermal comfort of people engaged in non-sedentary activity, recommending that use of the PMV index is restricted to activities with metabolic rates $<2$ MET. 


\section{Key Words: Exercise; Internal Environment; Metabolic Rate; PMV; Sport Facilities; Thermal}

Comfort

\section{Introduction}

The sport and recreation sector has an important role in society [1], with sport and sport-related activity in the top 15 industry sectors in England, generating over £20bn annually and supporting over 400,000 jobs [2]. Sport and active lifestyles are also a key factor in wider societal issues, with physical inactivity a leading risk factor for global mortality $[3,4]$. The essential nature of sporting activity is recognised by UK government policy [5]. Studies have shown that sport participation rates are influenced by environmental conditions [6].

The internal environment of buildings has been shown to have a significant impact on the wellbeing and satisfaction of occupants [7] and this is particularly relevant in sport facilities with common complaints resulting from poor conditioning including stuffiness and overheating in summer and cold draughts in winter. Inadequate lighting may cause visual discomfort [8] and insufficient ventilation may lead to poor air quality, moisture accumulation and odour [9]. At a critical level, the local environment can negatively influence the performance of an individual. Athletic performance becomes inhibited at extreme hot or cold temperatures [10-15], meaning competitive athletic events will be affected by poor quality environmental conditions. In extreme cases this can lead to an enhanced risk of injury [16]. Similarly, environmental conditions and air quality can negatively affect cognitive performance [17-23], which is significant in mixed-use buildings where examinations or teaching may take place. A combination of undesirable environmental factors may lead to individual dissatisfaction and ultimately a reluctance to engage in sporting activity [6].

One metric by which environmental conditions may be assessed is thermal comfort, which is defined as the state of mind that expresses satisfaction with the thermal environment [24]. As thermal comfort is desirable, methods to measure and predict the thermal comfort of occupants have been developed. The Predicted Mean Vote (PMV) thermal comfort index developed by Fanger [25] is the most widely used of these, and has been accepted into an international standard [26]. 
The popularity of the PMV index has naturally attracted investigation into its validity, particularly in real-world contexts. Although international standards governing its use state that "although developed for the work environment, it is applicable to other kinds of environment as well" [26], research suggests that the PMV index is a poor predictor of actual thermal sensation across a wide range of contexts [27-32]. Specifically, contextual factors found to influence predictive accuracy include: building type [29, 33], local climate [34], cultural and regional difference [35], age [36], activity [37], gender [38] and the characteristics of the occupied space [39-41]. Despite this criticism, PMV remains the most used thermal comfort index [31]. Whilst investigation into model validity is important, identification of poor performance is unhelpful without a corresponding attempt to improve predictive performance [29].

The PMV index has been developed to evaluate comfort under the assumption that the occupants are undertaking low up to moderate work, although as noted previously standards governing its use indicate that it is applicable to other kinds of environment [26]. Its guiding principle is that maximum comfort corresponds with neutral thermal sensation. This assumption has been challenged when considering contexts outside those used in the development of the PMV index, including during exercise [42-50]. Despite this, the PMV index has been applied to many situations where energetic leisure activities are likely to occur $[46,47,51-57]$, with several authors attempting to evaluate thermal comfort in sport facilities using a mixture of modelling [58-62], laboratory [43, 63, 64] and field $[47,54,65]$ methods. Existing studies are often limited in their scope or method [66], restricting their analysis to a subset of occupants, artificially limiting input values or applying the PMV index without providing detail on inputs and assumptions. This is relevant when considering that the PMV index places an upper limit on metabolic rate [26] that is routinely exceeded during exercise [67].

Inputs to the PMV index include environmental and personal parameters relevant to the human thermal balance, namely: air temperature; mean radiant temperature; humidity; air velocity; metabolic rate and clothing insulation. In field studies, environmental parameters may be measured directly [68], although this is often complex in practice [69] and the role of measurement accuracy is significant in PMV accuracy [70]. Measuring personal parameters is more complex, typically requiring laboratory- 
grade equipment and processes that involve thermal manikins [71] and calorimetry [72]. For this reason, in field studies the personal parameters are often assumed based on observation and comparison with tabulated reference values [32]. However, the PMV index is highly sensitive to personal parameters and the sensitivity of PMV to these assumptions is not habitually explored [73, 74].

The implications of using the PMV index in sport facilities, despite recommendations in the standard for its limited use [24, 26], requires further investigation. Additionally, existing PMV validation studies rely on databases of default values for predominantly sedentary (lower) metabolic rates [29, 75]. Thus, there is a need to understand how PMV accuracy is affected when a greater variation of metabolic rates are used in the model, to accommodate a broader range of occupant activities and, specifically, those that take place in sport facilities. This paper will concentrate on the metabolic rate, due to its heightened relevance in sport facilities.

The metabolic rate for an activity is often presented as a MET value, which is a ratio between the energy intensity of an activity and a reference metabolic rate. For thermal comfort calculations, 1 $\mathrm{MET}=58.2 \mathrm{~W} / \mathrm{m}^{2}$. International Standards for thermal comfort calculation and metabolic rate determination $[26,72]$ contain the methods for measuring metabolic rate and the reference tables of metabolic rates for common activities. Determining metabolic rate by observing an activity and referring to the corresponding tabulated reference value is the prevalent approach in field studies, however this standard approach has been observed to lack accuracy [76]. One source of error is the requirement for researchers to use their own interpretation to select a comparable metabolic rate from the reference values where a specific activity is not represented [24]. More accurate approaches to establish metabolic rate, for example using wearable technology such as heart rate $[73,77]$ and blood pressure [78] monitors, have been developed. However, the requirement for measurement equipment introduces the need for increased subject participation and has not been trialled in thermal comfort field tests comprising hundreds of participants. Consistent with the findings of Luo et al. [79] there is a need for improvement of methods using metabolic rate reference values. 
The aim of this paper is to evaluate the implications of using the PMV index to evaluate comfort in sport facilities. As the previously acknowledged guidance for its use [26] suggests PMV predictions may be imperfect for individuals engaged in energetic activity, this paper explores the potential to improve predictive accuracy though investigation of the following two issues relating to the metabolic rate used during PMV calculation:

i) Using an alternative reference database of metabolic rates: The metabolic rates contained in the thermal comfort standards $[26,72]$ are predominantly for sedentary or occupational activities rather than sport activities. This presents a possible source of error when applied to a sport facility; in the absence of sport specific values, the researcher is required to choose an activity deemed metabolically comparable for each sport that may take place in a sports hall. The Compendium of Physical Activities (CPA) [80] is an alternative and larger database of metabolic rates than that provided in the ISO standard [72], containing different activities that can be used where the MET data are not available in the ISO database. The MET values that make up the CPA are taken from robust laboratory classification studies, and are considered to be a valuable resource in studies of physiology and sport science [81]. Using the CPA for thermal comfort calculations may be problematic; however, given that MET values are presented using different units (W/kg as opposed to $\mathrm{W} / \mathrm{m}^{2}$ ), and so directly using MET values from the CPA may cause methodological uncertainty. This paper will investigate the impact of this difference on the PMV for the case study building.

ii) Varying MET weighting approach: When occupants undertake multiple activities with varying metabolic rates consecutively while in a building, researchers often simply use time-weighted average of the metabolic rates to input into PMV calculations [26]. However, this has been shown to cause overestimations in PMV, and not adequately account for the transient effects of metabolic activity and thermal sensation $[64,82,83]$. Furthermore, the insulating effect of clothing (clo) is reduced when the body moves, through increased relative air velocity compressing fabrics and by the 'pumping' effect as motion increases air exchange between the body surface and the external environment via cuffs, collars and sleeve openings [71, 84]. As metabolic rate influences insulating performance, applying an average metabolic rate may incorrectly estimate the actual reduction in 
clothing insulation. Thus, applying a time-weighted average metabolic rate to work cycles that include different activities may not be appropriate, and risks obscuring dynamic effects. To overcome this issue, rather than calculate a single PMV using the average MET rates this paper will evaluate the impact of calculating a time-weighted average PMV for the activity period, based on discreet PMV values generated for each activity phase [47].

Using a case study of a Multi-Purpose Sports Hall (MPSH), the aggregated discrepancy between the PMV and the occupant's actual thermal sensation vote (TSV) as reported via occupant survey was calculated. The effectiveness of novel modifications to the PMV method to reduce predictive bias and improve accuracy were then evaluated, incorporating an alternative database of metabolic rates, the CPA.

\section{Methodology}

This section first describes the case study building and environmental data collection that took place, as well as the occupant surveys that were undertaken. It then outlines the systematic analysis method taken to evaluate how uncertainty in MET assumptions impacts PMV scores. It then describes the approach taken to modifying the PMV method, and finally the method for comparing the enhanced PMV with the TSV of respondents is described.

\subsection{Case Study Building}

Data were collected during a 24-month monitoring campaign of a MPSH located on a university campus in Northern England. MPSHs are the most common indoor sport construction [56, 85], characterised by their 'one size fits all' nature, being of a suitable size and layout to accommodate a wide variety of activities. Internal and external images of the MPSH are shown in Figure 1, with dimensions and monitoring equipment location shown in Figure 2. The hall is of brick solid wall construction and heated by radiators connected to a central heating system. Heating is controlled by a central thermostat located in the adjoining lobby and provided during operating hours (07:00 - 22:00), with cooling via natural ventilation provided by openable windows controlled by the occupants. 

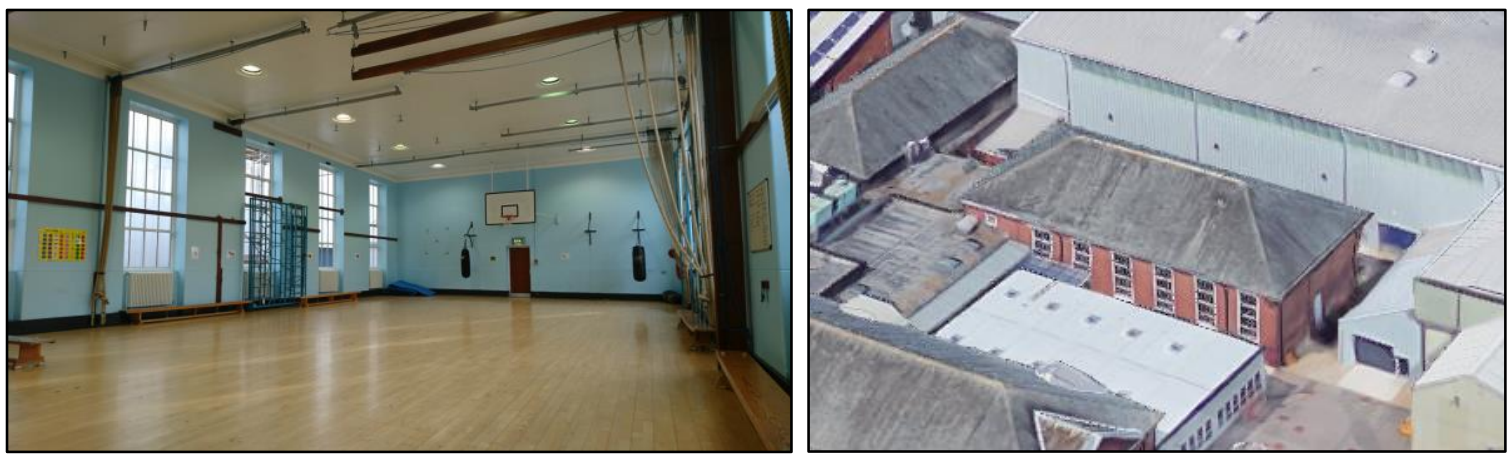

Figure 1: Internal (left) and external [86] (right) image of multi-purpose sport hall.

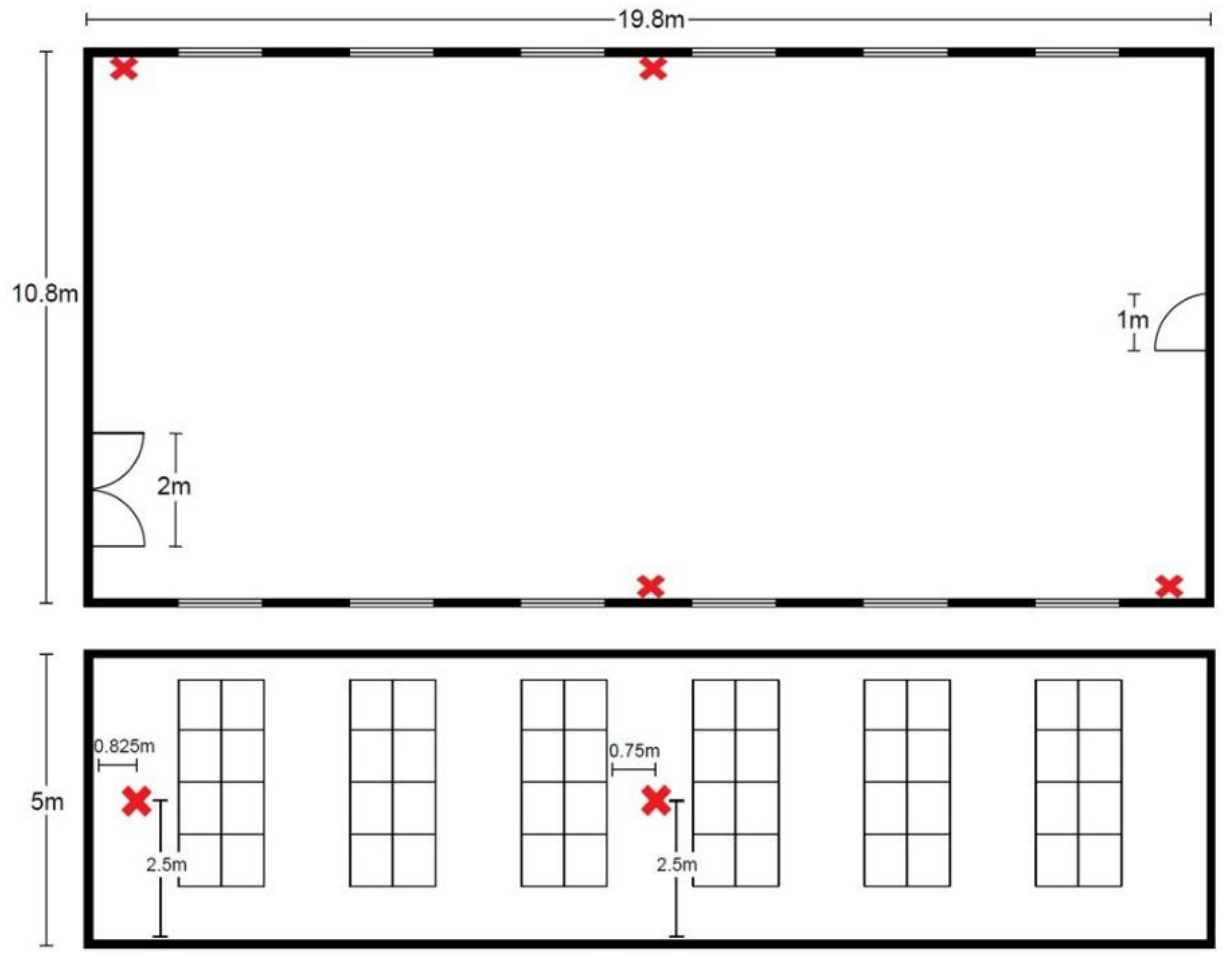

Figure 2: Floor plan (Top) and wall section (Bottom) of case study sports hall with monitoring equipment location indicated by red crosses.

\subsection{Environmental data}

Table 1 gives the characteristics of environmental measurement equipment. The practical use of the MPSH necessarily restricted sensor placement, thus measurement was restricted to the perimeter of the space and at a height that would reduce likelihood of tampering. Additionally, as equipment was installed for an extended and unattended period, effort to minimise obtrusion was made $[87,88]$. 
Table 1: Characteristics of environmental measurement equipment

\begin{tabular}{|l|c|c|}
\hline Variable & Units & Accuracy \\
\hline Air Temperature $\left(\mathrm{T}_{\mathrm{a}}\right)$ & ${ }^{\circ} \mathrm{C}$ & \pm 0.4 \\
\hline Mean Radiant Temperature $\left(\mathrm{t}_{\mathrm{r}}\right)$ & ${ }^{\circ} \mathrm{C}$ & \pm 0.4 \\
\hline Relative Air Velocity $\left(\mathrm{V}_{\mathrm{ar}}\right)$ & $\mathrm{m} / \mathrm{s}$ & $\pm 5 \%+0.1$ \\
\hline Relative Humidity (rh) & $\%$ & \pm 5 \\
\hline
\end{tabular}

As sensors could not be placed at an optimum location (i.e. the room centre) for practical reasons, to minimise the influence of sensor placement, temperature and humidity data were collected from 4 locations of the hall perimeter. Sensors were positioned to avoid direct sunlight, and the average value of all sensors was taken to represent conditions at the room centre. To provide further confidence in measurements, the assumption that average condition at the perimeter was a reasonable approximation of condition at the room centre was validated by two separate tests where measurements of environmental variables were taken from 11 evenly dispersed locations in the MPSH central space during an unoccupied period. Measurements from all 11 locations were found to be within instrumental measurement accuracy of perimeter conditions, suggesting negligible stratification and supporting the given assumption.

Mean radiant temperature for the room centre could not be measured directly due to the aforementioned impediment to the function of the MPSH and was therefore assumed equal to air temperature. This may obscure radiant effects and is acknowledged during the discussion of results. Air velocity was measured as a spot sample on 24 separate occasions at various times of day during the monitoring period, with all spot test measurements $\leq 0.2 \mathrm{~m} / \mathrm{s}$. A mean value of $0.15 \mathrm{~m} / \mathrm{s}$ was used for environmental air movement.

Existing studies evaluating comfort in sport facilities rely on short term measurement regimes, with spot-measurement of environmental variables taken alongside personal and subjective data capture $[47,51-55,65,89]$. This approach results in a limited range of both environmental and personal 
scenarios for PMV calculation. The long-term nature of the present study overcomes this limitation, incorporating a wide range of PMV input values displayed by Table 2 .

Table 2: Variable range observed during analysis

\begin{tabular}{|l|c|}
\hline Variable & Range \\
\hline Air Temperature $\left({ }^{\circ} \mathrm{C}\right)$ & $10.0-25.0$ \\
\hline Mean Radiant Temperature $\left({ }^{\circ} \mathrm{C}\right)$ & $10.0-25.0$ \\
\hline Relative Humidity (\%) & $44.0-70.0$ \\
\hline Air Velocity (m/s) & 0.15 \\
\hline Metabolic Rate (MET) & $1.60-8.80$ \\
\hline Clothing Insulation (clo) & $0.25-1.23$ \\
\hline
\end{tabular}

\subsection{Thermal sensation survey}

Subjective data were collected using a questionnaire developed according to BS EN ISO 10551:2001 [90], with additional questions concerning participant age, gender, activity and clothing for MET and clo determination. Participants were asked to rate their thermal sensation on the 7-point ASHRAE [24] scale shown by Figure 3 below.

\begin{tabular}{c|ccccccc} 
Response & $\mathbf{- 3}$ & $\mathbf{- 2}$ & $\mathbf{- 1}$ & $\mathbf{0}$ & $\mathbf{1}$ & $\mathbf{2}$ & $\mathbf{3}$ \\
\hline ASHRAE & Cold & Cool & Slightly & Neutral & Slightly & Warm & Hot \\
Scale (TSV) & & & cool & & warm & &
\end{tabular}

Figure 3: Thermal judgment scales used to record subjective perception

Data were collected during both heating (October - April) and non-heating (May - September) seasons [91], and thus, incorporate a wide range of internal conditions as shown by Table 2 . Participants were surveyed immediately following the conclusion of their session in the MPSH. Questionnaire metadata is shown in Table 3, with sampling occurring across a range of activities and 
subjects totalling a sample size of $n=126$. The MPSH is accessible to all university staff, students and members of the public with membership to use the sport and leisure facilities.

Table 3 Questionnaire metadata

\begin{tabular}{|c|c|c|c|c|}
\hline Activity & $\mathrm{n}$ & \multicolumn{2}{|c|}{ Participants } & n \\
\hline Abs Blast & 3 & \multirow{5}{*}{ 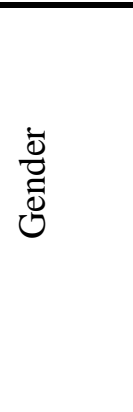 } & \multirow{3}{*}{$\begin{array}{l}\text { Male } \\
\text { Female }\end{array}$} & \\
\hline Basketball & 3 & & & 47 \\
\hline BodyTone & 12 & & & 79 \\
\hline Boxing & 8 & & & \\
\hline Circuits & 11 & & & \\
\hline Crossfit & 13 & \multirow{5}{*}{$\underset{<}{\infty}$} & $18-21$ & 36 \\
\hline HIIT & 16 & & $22-30$ & 42 \\
\hline Pilates & 3 & & $31-40$ & 8 \\
\hline Pump it up & 6 & & $41+$ & 40 \\
\hline Spinning & 18 & & & \\
\hline Table Tennis & 5 & \multicolumn{2}{|l|}{ Season } & $\mathbf{n}$ \\
\hline Teaching/Seminar & 24 & \multicolumn{2}{|l|}{ Heating } & 73 \\
\hline Testing & 4 & \multicolumn{2}{|l|}{ Cooling } & 53 \\
\hline
\end{tabular}

\subsection{Modifications to PMV method.}

This section outlines the systematic approach taken to modify PMV calculation to improve predictive accuracy in sports halls. Several decision-making stages were followed to produce multiple PMVs for each individual case, an overview of which is illustrated by Figure 4. The process is organised according to four stages:

Stage 1 considers the $232 \mathrm{~W} / \mathrm{m}^{2}$ limit to metabolic rate imposed by the PMV calculation. As this is likely to be exceeded during exercise, the limit is either applied or disregarded. 
Stage 2 considers the weighting method for activities composed of multiple metabolic rates, for example the warm up, peak and cool-down elements of a fitness class.

Stage 3 is the selection of the source from which to obtain the MET values required for the PMV calculation process (e.g. ISO or CPA).

Stage 4 is the calculation of a PMV for each case based on the decisions taken during stages 1-3, with each decision influencing the MET and clo inputs to the PMV index. This yields a total of 16 possible PMV values for each individual case. The calculation process as described provides a naming convention which is present in subsequent figures and expressed for all outputs. Names denote MET limited (L) or unlimited (U), the calculation process of weighted MET (WM) or weighted PMV (WP) and the MET value applied (ISO/CPA/CPArh/CPAsa).

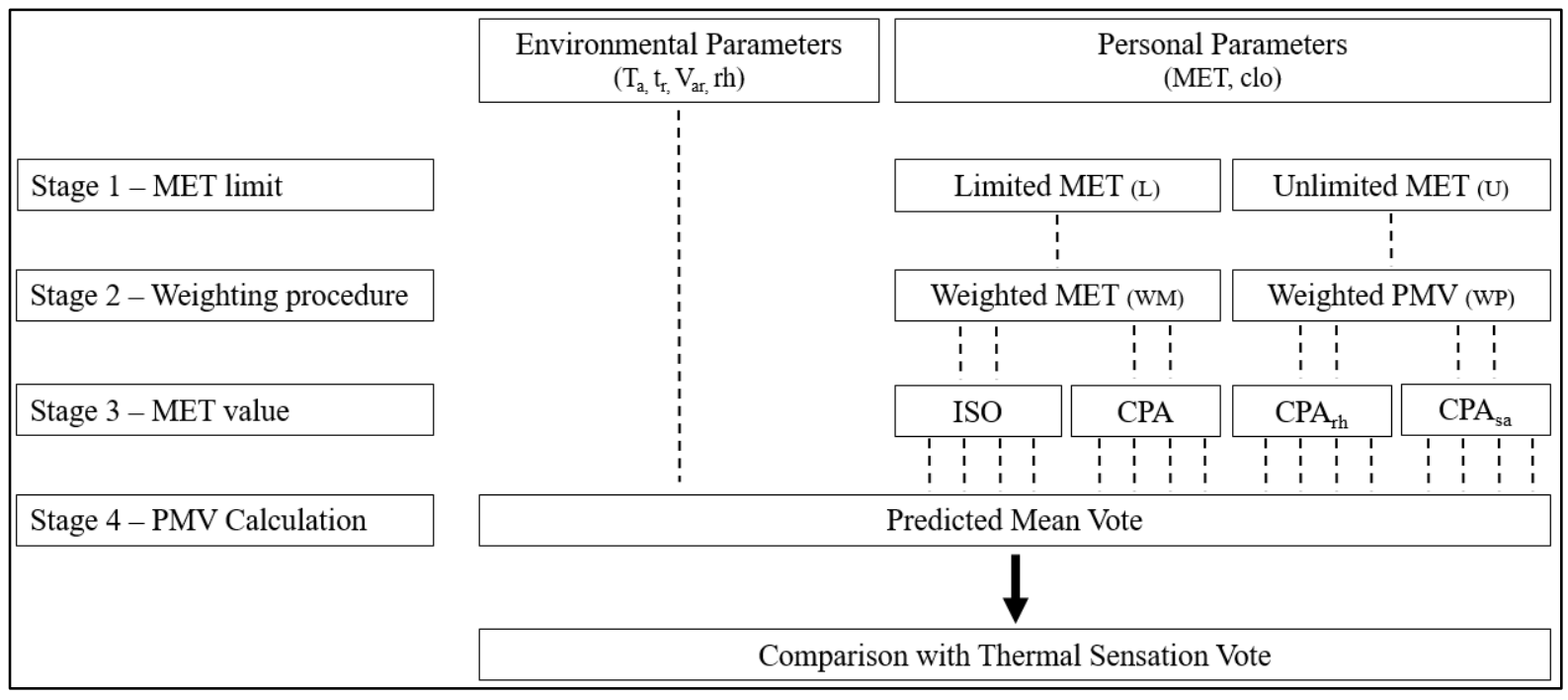

Figure 4 Schematic of methodological approach.

Clothing insulation is significant in the calculation of PMV, particularly when considering less insulative ensembles or ensembles with large areas of exposed skin [76]. Such clothing is common for sports apparel $[92,93]$. Participants were asked to identify the individual items of clothing they were wearing during subjective data collection, and these data were used to construct an ensemble for the determination of static clothing insulation. BS EN ISO 9920:2009 [71] provides an approach to determining clo; all clo values used for PMV calculation were derived from either a reference ensemble or similar ensemble with minor substitution. 
As discussed, when considering clothing insulation the influence of body movement and relative air velocity must be taken into account $[71,84,94]$. The calculation procedure to determine resultant clothing insulation following correction for dynamic effects is given in BS EN ISO 9920:2009 [71] and utilises a correction factor that is a function of both walking speed (which may be replaced by a function of metabolic rate for activities other than walking) and relative air velocity. Metabolic rate must therefore be defined before resultant clo can be calculated.

The weighting procedure for metabolic rate outlined in BS EN ISO 7730:2005 [26] results in a single MET value for use in the PMV calculation. Correcting static clo using an average MET derived from multiple activity phases potentially obscures the influence of varying activities on clothing insulation. For this reason, and owing to the significance of MET in the present study, during the second weighting approach given by equation 2 resultant clo values were defined separately for each activity phase, and applied accordingly in the calculation of the discreet PMV for each activity phase.

\subsubsection{Stage 1, Metabolic limit}

Although Fanger's initial experiments only extended to metabolic rates of $150 \mathrm{~W} / \mathrm{m}^{2}$ [25], when considering input values the international standard for PMV calculation identifies an upper limit for metabolic rate of $232 \mathrm{~W} / \mathrm{m}^{2}$, equivalent to 4 MET [26]. As discussed and shown by Table 4, many sport activities have a higher metabolic rate than that imposed by the PMV index. As such, the first modification evaluated is the removal of the upper limit during analysis to evaluate any effect on PMV accuracy.

2.4.2 Stage 2, Weighting procedure for multiple activity cycles

To accommodate activities composed of multiple metabolic rates (e.g. the warm up, peak and cooldown elements of a fitness class) two weighting approaches were considered during analysis. The duration of activity phases is shown by table 4 , and each weighting method accounts for the full 1hour duration of the activity. This is consistent with guidance in BS EN ISO 8996:2004 and BS EN ISO 7730:2005 which states that "for varying metabolic rates, a time-weighted average should be 
estimated during the previous 1-hour period" [26]. No activity included long rest periods, negating the Simonson effect [72].

BS EN ISO 8996:2004 [72] outlines a method for calculating a time-weighted average metabolic rate for a work cycle when it is composed of several activity phases each with different metabolic rates. This approach is described by equation 1 , where $\mathrm{M}$ is the average metabolic rate for the work cycle, $\mathrm{M}_{\mathrm{i}}$ is the metabolic rate of an activity phase, $\mathrm{t}_{\mathrm{i}}$ is the duration of the activity phase and $\mathrm{T}$ is the total duration of the work cycle and equal to the sum of $t_{i}$. Each session in the MPSH was observed to determine activity weighting, and the subsequent average metabolic rate used to compute PMV.

$$
\mathrm{M}=\frac{1}{\mathrm{~T}} \sum_{\mathrm{i}=1}^{\mathrm{n}} \mathrm{M}_{\mathrm{i}} \mathrm{t}_{\mathrm{i}}
$$

A time-weighted metabolic rate may obscure transient metabolic effects of different activity phases $[64,82,83]$. A second weighting approach was considered to overcome this. PMV was calculated for each activity phase using its MET and resultant clo. These discreet PMV values were then used to create a time-weighted PMV for the activity as a whole [47]. This is described by equation 2, where $\mathrm{P}$ is the average PMV for the work cycle, $\mathrm{P}_{\mathrm{i}}$ is the PMV calculated for an activity phase, $\mathrm{t}_{\mathrm{i}}$ is the duration of the activity phase and $\mathrm{T}$ is the total duration of the work cycle and equal to the sum of $\mathrm{t}_{\mathrm{i}}$.

$$
\mathrm{P}=\frac{1}{\mathrm{~T}} \sum_{\mathrm{i}=1}^{\mathrm{n}} \mathrm{P}_{\mathrm{i}} \mathrm{t}_{\mathrm{i}}
$$


Table 4 Activity Durations

\begin{tabular}{|l|c|c|c|c|}
\hline Activity & Warmup (min) & Peak (min) & Cooldown (min) & Total (min) \\
\hline Abs Blast & 10 & 40 & 10 & 60 \\
\hline Basketball & 10 & 45 & 5 & 60 \\
\hline BodyTone & 10 & 40 & 10 & 60 \\
\hline Boxing & 15 & 30 & 15 & 60 \\
\hline Circuits & 10 & 40 & 10 & 60 \\
\hline Crossfit & 10 & 40 & 10 & 60 \\
\hline HIIT & 10 & 40 & 10 & 60 \\
\hline Pilates & 5 & 50 & 5 & 60 \\
\hline Pump it up & 10 & 40 & 10 & 60 \\
\hline Spinning & 10 & 40 & 10 & 60 \\
\hline Table Tennis & 0 & 60 & 0 & \\
\hline Teaching/Seminar & 0 & 60 & 0 & 60 \\
\hline Testing & 0 & & & \\
\hline
\end{tabular}

\subsubsection{Stage 3, MET reference value.}

The metabolic rate is highly influential in PMV calculation [74]; however, the majority of thermal comfort field studies rely on reference to tabulated values for activities. This approach is unlikely to change due to its convenience and low requirement for human participation. To evaluate the potential for improvement in this area, in addition to BS EN ISO 8996:2004 reference values [72], a second metabolic rate database, the Compendium of Physical Activities (CPA)[80], is introduced.

Metabolic rate may be presented as a MET value, which corresponds in a linear relationship to energy expenditure. An activity with metabolic rate of 2 MET has twice the metabolic rate as a 1 MET activity. Although both BS EN ISO 8996:2004 [72] and the CPA report the metabolic rate of activities in METs, they use different units in their ratio setting: 1 MET in BS EN ISO 8996:2004 [72] 
corresponds to $58.2 \mathrm{~W} / \mathrm{m}^{2}$ whereas in the CPA 1 MET is equal to $1.162 \mathrm{~W} / \mathrm{kg}$. To use CPA values in PMV calculation a conversion factor is required. This is because the PMV calculation specifies a $\mathrm{W} / \mathrm{m}^{2}$ metabolic rate, and body weight and surface area do not scale equally and linearly due to variations in body shape and composition [95]. Two approaches to attaining a conversion factor are considered.

Firstly, as both standards refer to a 'reference human' of 70kg weight $[67,72]$, it is possible to obtain a conversion. The body surface area of $1.8 \mathrm{~m}^{2}$ given in BS EN ISO 8996:2004 [72] allows us to draw a comparison between METs relative to the reference human:

BS EN ISO 8996:2004: 1 MET $=58.2 \mathrm{~W} / \mathrm{m}^{2} \quad=104.76 \mathrm{~W}$

CPA: $\quad 1 \mathrm{MET}=1.162 \mathrm{~W} / \mathrm{kg} \quad=81.34 \mathrm{~W}$

It follows that MET values in the CPA may incur an overestimation of metabolic rate (and resultant warmth sensation) if applied directly to the ISO method, as shown by Table 5. By using the characteristics of the reference human, we may convert CPA MET values relative to the reference human $\left(\mathrm{CPA}_{\mathrm{rh}}\right)$ using equation 3, the effect of which is illustrated in Table 4.

$$
C P A_{r h}=\frac{C P A \times 81.34}{104.76}
$$

Since the agreement of the two reference data sets is unknown, a second method has been developed to harmonise CPA MET with the ISO. This is shown by Figure 5, which plots the MET value from BS EN ISO 8996:2004 [72] against the MET value from the CPA for a series of common activities where such pairs exist. As can be seen, there is good agreement between the two datasets $\left(r^{2}=0.96\right)$ which suggests commonality. The CPA MET values are regularly higher than their respective ISO equivalent, which is consistent with the relationship described previously. Thus, the linear relationship between the METs for similar activities (shown by equation 4) constitutes another approach to align CPA MET values with BS EN ISO 8996:2004 [72](CPA $\left.{ }_{\mathrm{sa}}\right)$. 


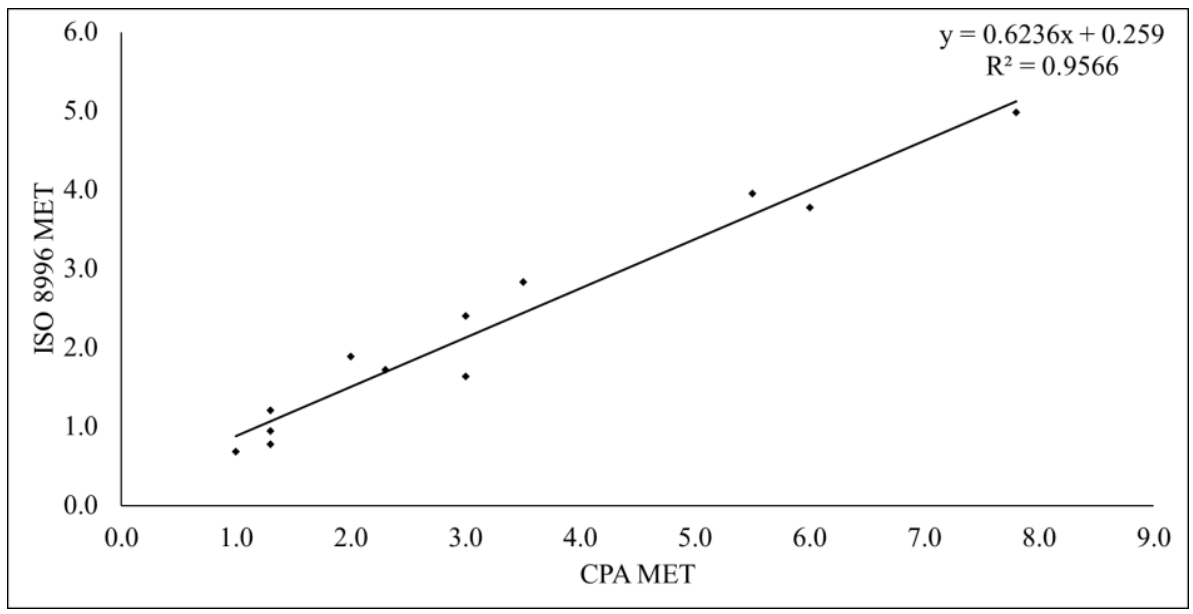

Figure 5 Comparison of semantically similar activities in MET databases.

$$
\mathrm{CPA}_{\mathrm{sa}}=(\mathrm{CPA} \times 0.6236)+0.259
$$

Consequently, four variations of MET values are considered for use in the PMV calculation:

1) ISO, using values directly from BS EN ISO 7730:2005;

2) CPA, using values directly from the CPA;

3) $\mathrm{CPA}_{\mathrm{rh}}$, using CPA values with 'reference human' conversion given by equation 3 and

4) $\mathrm{CPA}_{\mathrm{sa}}$, using CPA values with 'similar activities' conversion given by equation 4.

This research will investigate the impact of selecting any one of these over another. It is important to note that following the conversion methods outlined, the metabolic rates contained in the CPA are not fundamentally changed and they retain their relative relationship within each iteration; the conversion serves to convert the values from $\mathrm{W} / \mathrm{kg}$ to $\mathrm{W} / \mathrm{m}^{2}$. Table 5 shows the impact of each approach on activity MET. 
Table 5 Average MET values for activities according to ISO weighting approach

\begin{tabular}{l|cccc}
\multirow{2}{*}{ Activity } & \multicolumn{4}{|c}{ Average Metabolic Rate (MET) } \\
& ISO & CPA & CPA $_{\mathbf{R H}}$ & CPASA $_{\text {SA }}$ \\
\hline Pilates & 1.9 & 2.8 & 2.1 & 2.0 \\
Basketball & 4.0 & 5.1 & 4.0 & 3.4 \\
Boxing & 3.9 & 4.4 & 3.4 & 3.0 \\
Circuits & 3.2 & 3.6 & 2.8 & 2.5 \\
Teaching & 1.9 & 3.5 & 2.7 & 2.4 \\
Fitness Class & 4.7 & 6.0 & 4.6 & 4.0 \\
Netball & 4.0 & 5.1 & 4.0 & 3.4 \\
Rugby & 4.0 & 5.0 & 3.9 & 3.4 \\
Spinning & 4.7 & 6.6 & 5.2 & 4.4 \\
Table Tennis & 2.3 & 3.5 & 2.7 & 2.4 \\
Testing & 2.0 & 3.0 & 2.3 & 2.1 \\
& & & &
\end{tabular}

\subsubsection{Stage 4, Calculation of PMV}

In the final stage, a single PMV is calculated for each case according to the decisions taken during Stages 1-3; these decisions influence both the MET and clo values used during calculation. The result is a total of $16 \mathrm{PMV}$ values, which incorporate each possible decision path.

\subsection{PMV Validation Procedure}

PMV is intended to be a representative expression of the thermal vote of a population under specific steady state parameters. As such, it is not appropriate to evaluate PMV by its correlation with a single thermal sensation vote (TSV) [29]. Such an approach would require many TSVs under identical 
conditions, whereas the present dataset is from many combinations of environmental and personal conditions in a field setting. To overcome this issue, the reliability of each PMV approach is evaluated by considering the aggregated discrepancy between TSV and PMV for the whole sample $[29,75]$. Root-mean-square deviation (RMSD), which represents the average difference between predicted and measured values, was used to define predictive accuracy with the acceptable level of accuracy defined as being within the standard deviation of TSV [75]. In addition, predictive bias was calculated to evaluate over or under-estimation, with a positive value indicating under-estimation and a negative value indicating over-estimation. The acceptable bias of \pm 0.25 proposed by Humphreys and Nicol [29] was adopted during analysis. The calculation procedures for RMSD and bias are given by equations 5 and 6 respectively.

$$
\begin{aligned}
\text { RMSD } & =\sqrt{\frac{\sum\left(\mathrm{x}_{\text {measured }}-\mathrm{x}_{\text {predicted }}\right)^{2}}{\mathrm{n}}} \\
\text { Bias } & =\frac{\sum\left(\mathrm{x}_{\text {measured }}-\mathrm{x}_{\text {predicted }}\right)}{\mathrm{n}}
\end{aligned}
$$

\section{Results and Discussion}

\subsection{PMV evaluation}

Initial evaluation considers the discrepancy between PMVs generated and how these compare to the subjective thermal sensation according to the ASHRAE scale (TSV), as this is the intended output of the PMV index. Figure 6 shows the RMSD and bias for all calculation methods of PMV relative to TSV. As a point of reference, the original PMV method is displayed as the first on the $\mathrm{x}$-axis (L.WM.ISO). 

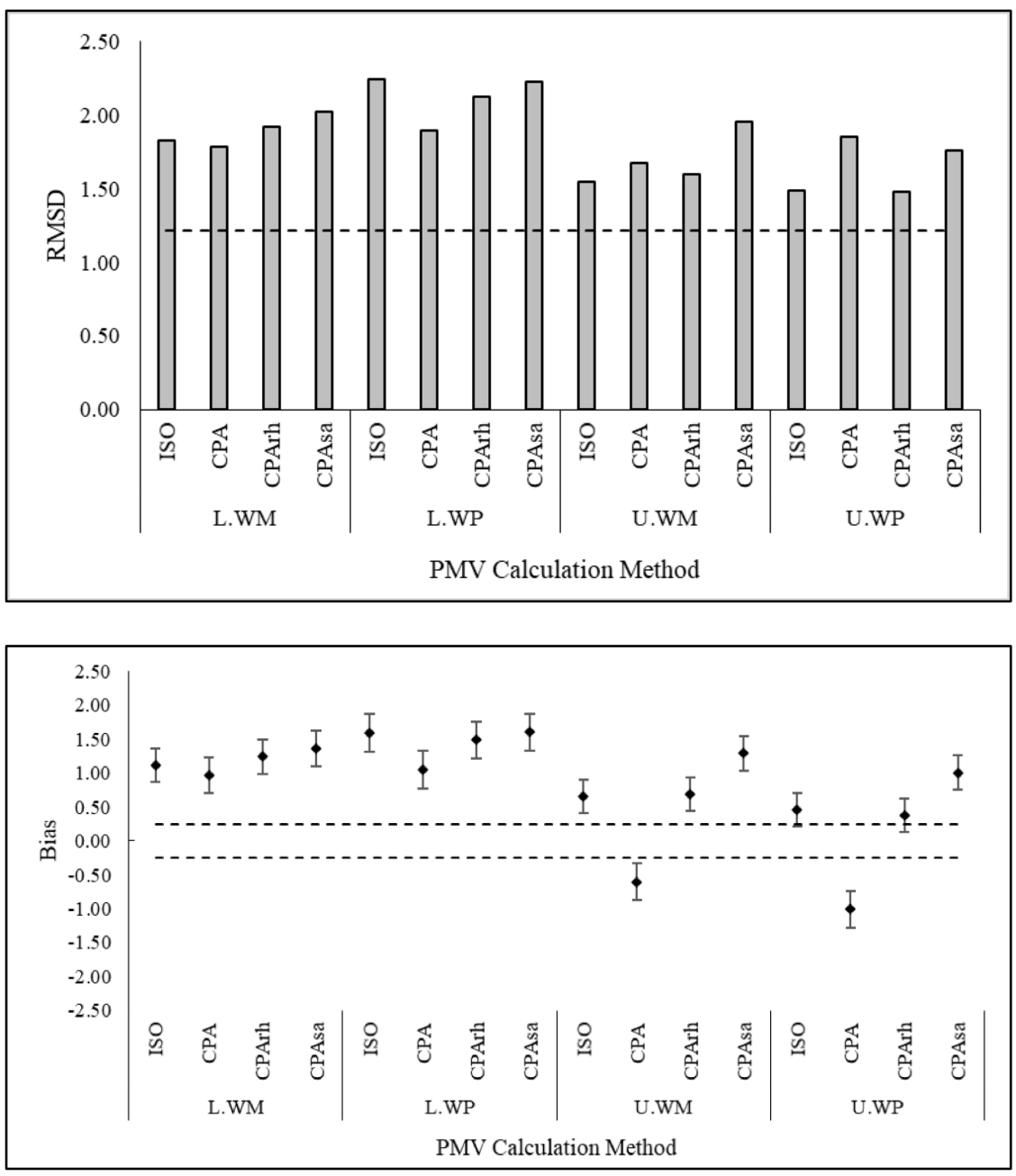

Figure 6 RMSD (top) and Bias (bottom) presented in thermal sensation units for all PMV calculation methods using all cases $(n=126)$. Conditions for good predictive accuracy are indicated by the dashed line i.e. RMSD below standard deviation of TSV, bias $0 \pm 0.25$. Bias values include $95 \%$ confidence interval.

The results suggest that the methodological modifications applied during PMV calculation were successful in reducing predictive bias to within acceptable limits in two cases: U.WP.ISO and

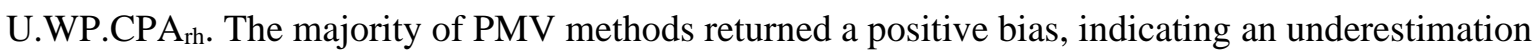
of thermal sensation. The exception to this observation are methods applying unlimited CPA MET values, which supports the use of conversion factors addressed in section 2.4.3. The performance of $\mathrm{CPA}_{\mathrm{rh}}$, attaining the lowest bias, suggests that this new method of determining metabolic rate may present an advantage over existing metabolic rate determination methods. 
Despite observed improvement in bias, when considering the full dataset, no PMV calculation method accomplished an RMSD value below the standard deviation of $\mathrm{TSV}_{\mathrm{a}}$, suggesting an unacceptable degree of variability in prediction. The finding of this analysis is, therefore, that even with the improvement arising from modifications the PMV index its use should be discouraged for all occupants of a MPSH. This implies that the current use of PMV as a tool for evaluating and controlling comfort and conditions in sport facilities prevalent in the literature may not be appropriate. PMV has been shown to be a good predictor of thermal sensation at lower metabolic rates [29]. To explore the influence of metabolic rate, the data were split into two populations according to their ISO MET level: $M E T \leq 2(n=31)$ and MET $>2(n=95)$. The limit of 2 MET aligns with recommendations in alternative standards for PMV use [24] and the point where bias has been observed to increase in previous research [29]. The PMV calculation methods were then evaluated using these two separate datasets. Figures 7 and 8 display the RMSD and bias for those activities MET $\leq 2$ and $>2$ MET respectively.

The RMSD for activities with MET $\leq 2$ improves in all calculation methods; notably so for the unmodified PMV method. It is possible that the small sample size and inherent subjectivity of thermal sensation will offer sufficient explanation for RMSD values exceeding TSV standard deviation in the present study. Additionally, the zero value for bias falls within the confidence limit for all PMV calculation methods. This suggests that for lower metabolic rate activities such as pilates and teaching, the standard PMV method is sufficiently robust in predicting thermal sensation in a sport facility. Furthermore, this indicates that existing metabolic rate limits of <4MET may require reduction to increase the likelihood of accurate prediction and restrict the use of PMV to evaluate environments where occupants are non-sedentary. 

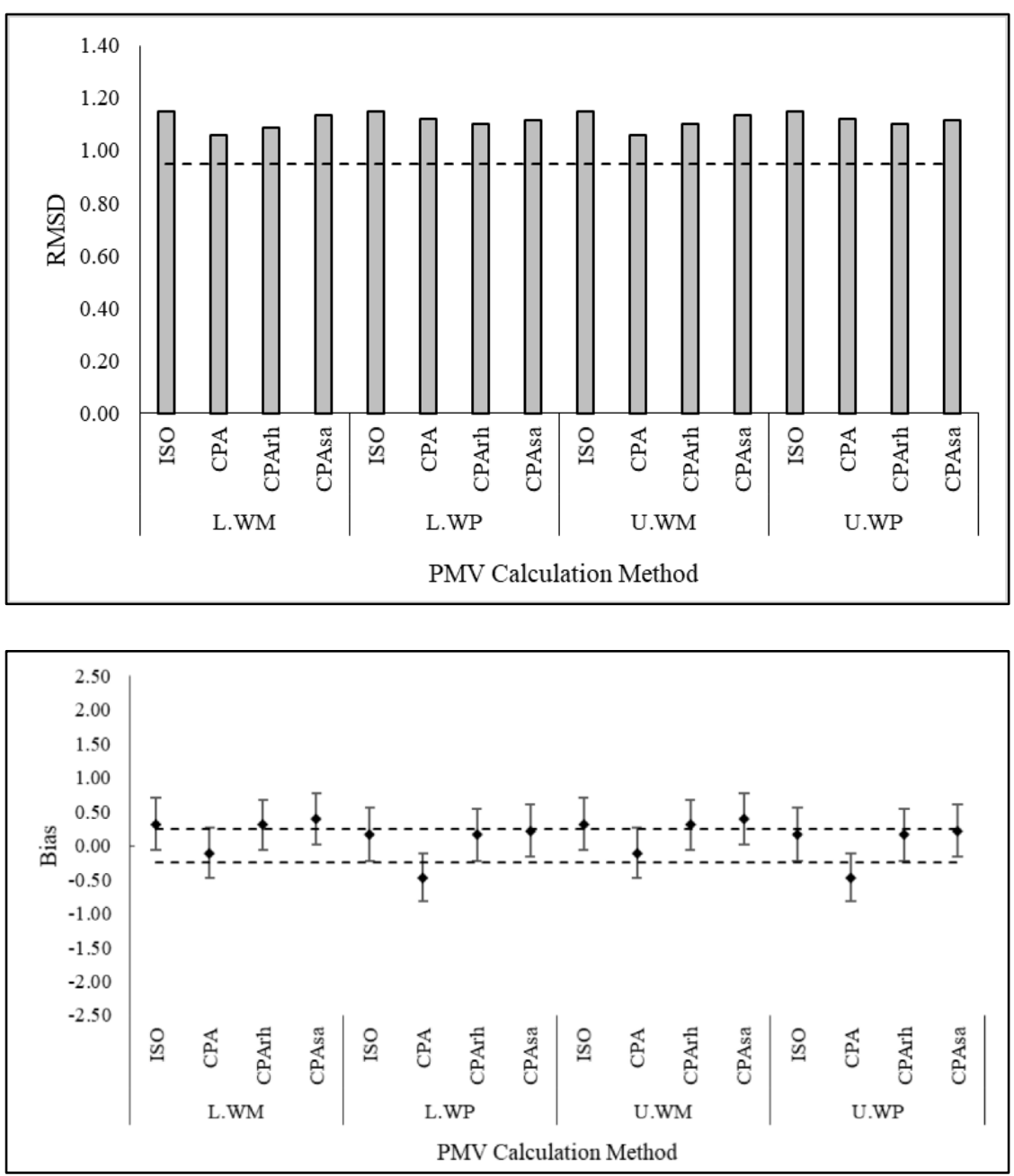

Figure 7 RMSD (top) and Bias (bottom) presented in thermal sensation units for all PMV calculation methods using cases where MET $\leq 2(n=31)$. Conditions for good predictive accuracy are indicated by the dashed line i.e. RMSD below standard deviation of TSV, bias $0 \pm 0.25$. Bias values include $95 \%$ confidence interval.

The opposite effect is observed when considering activities with MET $>2$, with RMSD increasing for all calculation methods. As with the full dataset, only 2 methods attained acceptable bias within their confidence interval. The majority of PMV methods continue to return a positive bias, indicating an underestimation of thermal sensation. As with the analysis of the full dataset, accuracy appears to improve as a result of methodological decisions, namely the removal of the MET limit and the application of a weighted PMV. In summary, the data suggest that even with improvement in prediction resulting from methodological modification, the PMV method produces an unreliable prediction of thermal sensation for occupants of a sport facility when engaged in activities $>2$ MET. 

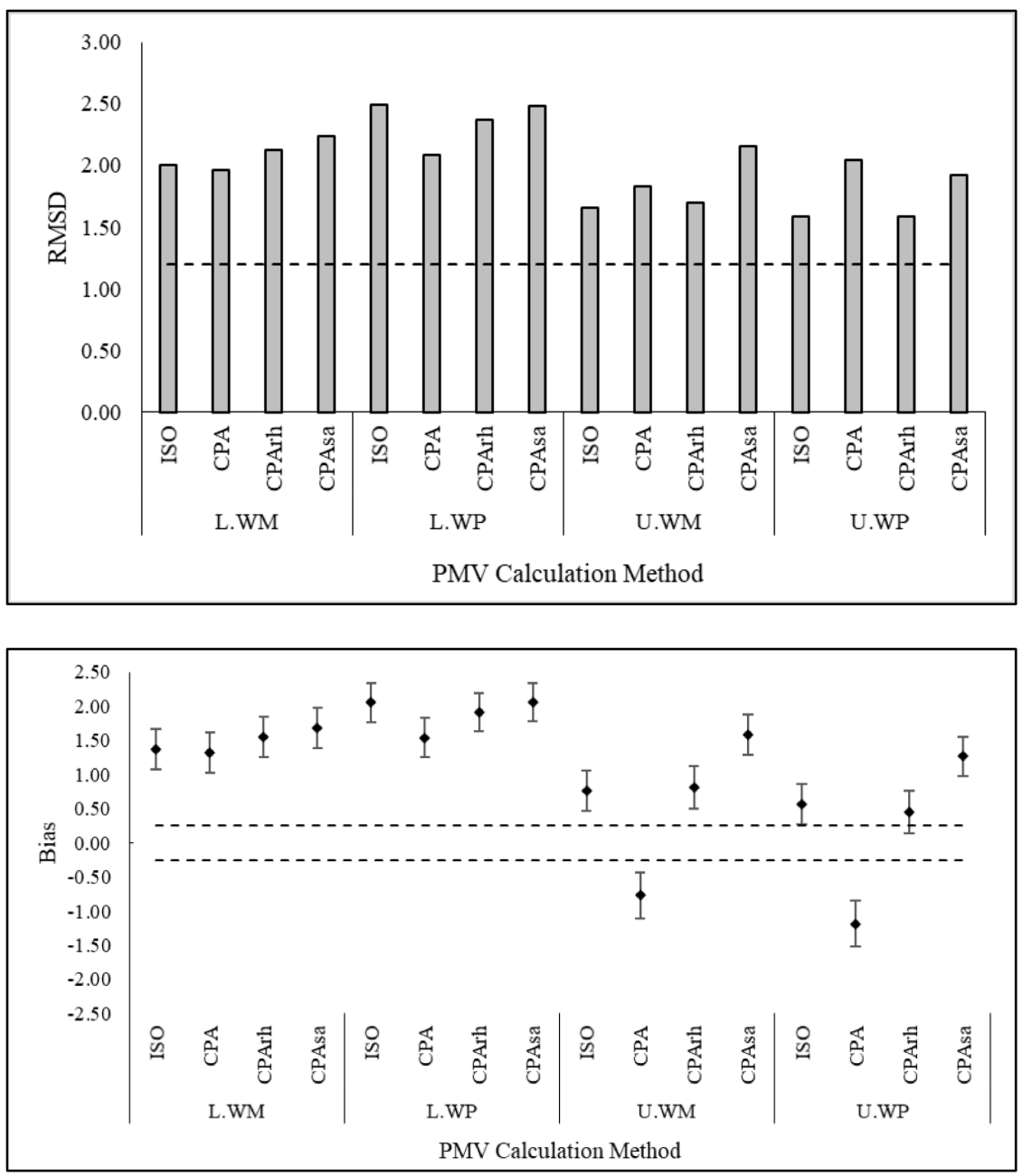

Figure 8 RMSD (top) and Bias (bottom) presented in thermal sensation units for all PMV calculation methods using cases where MET $>2(n=95)$. Conditions for good predictive accuracy are indicated by the dashed line i.e. RMSD below standard deviation of TSV, bias $0 \pm 0.25$. Bias values include $95 \%$ confidence interval.

This finding broadly supports existing studies [29, 75]; however, the data suggest an alternative conclusion regarding thermal sensation. Whereas other studies have found an overestimation in the prediction of thermal sensation in a sport environment $[29,54]$ i.e. they predict occupants will be warmer than observed, the present study appears to show an underestimation in the prediction of warmth sensation for individuals engaged in >2 MET activity in a MPSH.

One possible explanation for this is the presence of a source of radiant heat that is not captured by environmental monitoring and thus absent from the PMV inputs. This is considered unlikely; the 
MPSH does not have an infrared heating system, and any influence from direct sunlight is assumed to be sporadic due to occupant movement and seasonal fluctuation and thus not likely to influence overall thermal evaluation to the observed degree.

The underestimation may also arise from excessive heat loss in the model caused by low clothing insulation. Ensembles with clo $<0.6$ are subject to an interpolation that accounts for the increased heat loss of exposed skin, which is assumed for a low-insulation ensemble [71]. Many of the observed ensembles offered little insulation, and thus were subject to this correction; however, some of these presented a high degree of body coverage (e.g. leggings and base layers) leading to a potential overestimation of heat loss from nude skin. Sports apparel is not well represented in existing clothing databases, and as such it may be the case that their effective insulation is underestimated, a hypothesis the present study is not able to evaluate.

\section{Conclusions}

The limitations stated in BS EN ISO 7730:2005 [26] suggest the PMV index should not be used to evaluate the thermal sensation of individuals with an elevated metabolic rate. Despite this, the PMV index is commonly used in academic studies to evaluate environments where occupants frequently undertake high metabolic activities (including sport and exercise). This presented a need for the accuracy of PMV in a sport facility context to be evaluated.

The analysis presented confirms that, if used as directed according to BS EN ISO 7730:2005 [26], there exists a serious limitation in the predictive accuracy of the PMV index when used in a sport facility context. To overcome this, methodological modifications were made concerning the upper limit to metabolic rate, the approach to weighting activities with multiple exercise phases and the source of reference metabolic rates. The modifications were successful in reducing bias in PMV prediction, suggesting potential for their application in mixed use facilities with lower intensity metabolic activity such as theatres or factories.

The introduction of corrected metabolic values from the Compendium of Physical Activities presents a possible advantage over currently applied metabolic rate databases. The comprehensive list of 
activities reduces the requirement for the researcher to use their own judgement for MET selection when evaluating an activity not listed in the ISO thermal comfort standards. Additionally, although the effect was small, the performance of the $\mathrm{CPA}_{\mathrm{rh}}$ conversion in attaining the lowest bias suggests that this new method of determining metabolic rate may present further advantage over existing methods. Further research, applying the present methods to a larger dataset, is needed for confirmation.

Despite achieving a reduction in predictive bias, modifications were unable to improve predictive accuracy for activities $>2$ MET to an acceptable level. This presents two key findings: firstly, that existing recommendations limiting PMV to activities $<4$ MET may require amending with further restriction and secondly, that the prevalent use of the PMV index to evaluate comfort in sport facilities in current literature may not be reliable.

Finally, where previous studies have found an overestimation in thermal sensation for activities with a higher metabolic rate, the present study observed an underestimation of warmth sensation by the PMV index. This is hypothesised to be the result of an overestimation of heat loss for sports apparel. Further research to define the heat loss characteristics of sport apparel is needed.

\section{Declarations of Interest}

None.

\section{Funding}

No Funding.

\section{Acknowledgements}

The authors wish to thank the study participants who provided their subjective evaluations and Leeds Beckett University Estates for access to the case study building.

\section{References}

[1] Sport England, Active lives survey 2015-16: Year 1 report, Sport England, London, 2017.

[2] Sport England, Economic value of sport in England, London, 2013. 
[3] DOH, Impact of physical activity and diet on health, in: D.o. Health (Ed.) The Stationery Office, London, UK, 2015.

[4] DHSC, UK Chief Medical Officers' Physical Activity Guidelines in: D.o.H.a.S. Care (Ed.) GOV.UK, Online, 2019.

[5] DOH, Get active to get healthy, in: D.o. Health (Ed.) The Stationary Office, Online, 2013.

[6] A.L. Wagner, F. Keusch, T. Yan, P.J. Clarke, The impact of weather on summer and winter exercise behaviors, Journal of Sport and Health Science 8(1) (2019) 39-45.

[7] Sport England, Sports halls design and layouts: Updated and combined guidance, Design Guidance Note, Sport England, London, 2012.

[8] L. Edwards, P. Torcellini, Literature Review of the Effects of Natural Light on Building Occupants, National Renewable Energy Laboratory, USA, 2002.

[9] Y. Al horr, M. Arif, M. Katafygiotou, A. Mazroei, A. Kaushik, E. Elsarrag, Impact of indoor environmental quality on occupant well-being and comfort: A review of the literature, International Journal of Sustainable Built Environment (2016).

[10] J.R. Brotherhood, Heat stress and strain in exercise and sport, Journal of Science and Medicine in Sport 11(1) (2008) 6-19.

[11] M.R. Ely, S.N. Cheuvront, W.O. Roberts, S.J. Montain, Impact of Weather on Marathon-Running Performance, Medicine \& Science in Sports \& Exercise 39(3) (2007) 487-493.

[12] A.D. Flouris, Z.J. Schlader, Human behavioral thermoregulation during exercise in the heat, Scandinavian Journal of Medicine \& Science in Sports 25 (2015) 52-64.

[13] S.J. Murray, R.J. Shephard, M.W.M. Radomski, Physiological changes in women during exercise in cold environments, International Journal of Biometeorology 30(4) (1986) 301-306.

[14] A. Quirion, L. Laurencelle, L. Paulin, A. Therminarias, G.R. Brisson, A. Audet, S. Dulac, P. Vogelaere, Metabolic and hormonal responses during exercise at $20^{\circ}, 0^{\circ}$ and $-20^{\circ} \mathrm{C}$, International Journal of Biometeorology 33(4) (1989) 227-232.

[15] A.J. Tatterson, A.G. Hahn, D.T. Martini, M.A. Febbraio, Effects of heat stress on physiological responses and exercise performance in elite cyclists, Journal of Science and Medicine in Sport 3(2) (2000) 186-193.

[16] E.E.F. Scott, D.F. Hamilton, R.J. Wallace, A.Y. Muir, A.H.R.W. Simpson, Increased risk of muscle tears below physiological temperature ranges, Bone Joint Res 5(2) (2016) 61-65.

[17] Z. Bakó-Biró, D.J. Clements-Croome, N. Kochhar, H.B. Awbi, M.J. Williams, Ventilation rates in schools and pupils' performance, Building and Environment 48 (2012) 215-223.

[18] D.A. Coley, R. Greeves, B.K. Saxby, The effect of low ventilation rates on the cognitive function of a primary school class, International Journal of Ventilation 6(2) (2007) 107-112.

[19] R. Gupta, A. Howard, An empirical investigation of the link between indoor environment and workplace productivity in a UK office building, PLEA 2018 : Smart and Healthy within the 2-degree Limit, School of Architecture, The Chinese University of Hong Kong, Hong Kong, China, 2019, pp. 427432.

[20] K. Ito, S. Murakami, T. Kaneko, H. Fukao, Study on the productivity in classroom (part 2) realistic simulation experiment on effects of air quality/thermal environment on learning performance, $\mathrm{HB}$ 2006 - Healthy Buildings: Creating a Healthy Indoor Environment for People, 2006, pp. 207-212. [21] A. Uzelac, N. Gligoric, S. Krco, A comprehensive study of parameters in physical environment that impact students' focus during lecture using Internet of Things, Computers in Human Behavior 53 (2015) 427-434.

[22] P. Wargocki, D.P. Wyon, The Effects of Moderately Raised Classroom Temperatures and Classroom Ventilation Rate on the Performance of Schoolwork by Children (RP-1257), HVAC\&R Research 13(2) (2007) 193-220.

[23] A.J. Yeganeh, G. Reichard, A.P. McCoy, T. Bulbul, F. Jazizadeh, Correlation of ambient air temperature and cognitive performance: A systematic review and meta-analysis, Building and Environment 143 (2018) 701-716. 
[24] ASHRAE, Standard 55-2017 - Thermal environmental conditions for human occupancy, American Society of Heating, Refrigerating and Air-Conditioning Engineers, 2017.

[25] P.O. Fanger, Thermal Comfort, Danish Technical Press, Copenhagen, 1970.

[26] BSI, BS EN ISO 7730:2005 Ergonomics of the thermal environment. Analytical determination and interpretation of thermal comfort using calculation of the PMV and PPD indices and local thermal comfort criteria, British Standards Institution, London, UK, 2006.

[27] L.M. Chamra, W.G. Steele, K. Huynh, The uncertainty associated with thermal comfort, ASHRAE Transactions (Annual meeting, Kansas City, USA) (2003) pp. 356-365.

[28] T. Cheung, S. Schiavon, T. Parkinson, P. Li, G. Brager, Analysis of the accuracy on PMV - PPD model using the ASHRAE Global Thermal Comfort Database II, Building and Environment 153 (2019) 205-217.

[29] M.A. Humphreys, F.J. Nicol, The validity of ISO-PMV for predicting comfort votes in every-day thermal environments, Energy and Buildings 34(6) (2002) 667-684.

[30] M.A. Humphreys, F. Nicol, S. Roaf, Adaptive Thermal Comfort: Foundations and Analysis, Routledge, UK, 2016.

[31] J. van Hoof, Forty years of Fanger's model of thermal comfort: comfort for all?, Indoor Air 18(3) (2008) 182-201.

[32] R. de Dear, G.S. Brager, Developing an Adaptive Model of Thermal Comfort and Preference, ASHRAE Transactions 104(1) (1998).

[33] P.O. Fanger, J. Toftum, Extension of the PMV model to non-air-conditioned buildings in warm climates, Energy and Buildings 34(6) (2002) 533-536.

[34] Y.H. Yau, B.T. Chew, A review on predicted mean vote and adaptive thermal comfort models, Building Services Engineering Research \& Technology 35(1) (2014) 23-35.

[35] R. Maiti, PMV model is insufficient to capture subjective thermal response from Indians, International Journal of Industrial Ergonomics 44(3) (2014) 349-361.

[36] S.t. Mors, J.L.M. Hensen, M.G.L.C. Loomans, A.C. Boerstra, Adaptive thermal comfort in primary school classrooms: Creating and validating PMV-based comfort charts, Building and Environment 46(12) (2011) 2454-2461.

[37] E.E. Broday, J.A. Moreto, A.A.d.P. Xavier, R. de Oliveira, The approximation between thermal sensation votes (TSV) and predicted mean vote (PMV): A comparative analysis, International Journal of Industrial Ergonomics 69 (2019) 1-8.

[38] F. Schaudienst, F.U. Vogdt, Fanger's model of thermal comfort: a model suitable just for men?, Energy Procedia 132 (2017) 129-134.

[39] C. Chun, A. Kwok, A. Tamura, Thermal comfort in transitional spaces-basic concepts: literature review and trial measurement, Building and Environment 39(10) (2004) 1187-1192.

[40] S.C.M. Hui, J. Jie, Assessment of thermal comfort in transitional spaces, Joint Symposium 2014: Change in Building Services for Future, Hong Kong, 2014, p. 13.

[41] Y. Li, S. Geng, X. Zhang, H. Zhang, Study of thermal comfort in underground construction based on field measurements and questionnaires in China, Building and Environment 116 (2017) 45-54. [42] S.P. Corgnati, M. Filippi, S. Viazzo, Perception of the thermal environment in high school and university classrooms: Subjective preferences and thermal comfort, Building and Environment 42(2) (2007) 951-959.

[43] N. Gerrett, Y. Ouzzahra, S. Coleby, S. Hobbs, B. Redortier, T. Voelcker, G. Havenith, Thermal sensitivity to warmth during rest and exercise: a sex comparison, European journal of applied physiology 114(7) (2014) 1451.

[44] A. Oertel, R. Emmanuel, P. Drach, Assessment of predicted versus measured thermal comfort and optimal comfort ranges in the outdoor environment in the temperate climate of Glasgow, UK, Building Services Engineering Research \& Technology 36(4) (2015) 482-499.

[45] T. Parkinson, R. de Dear, Thermal pleasure in built environments: physiology of alliesthesia, Building Research \& Information 43(3) (2015) 288-301. 
[46] A. Pezzoli, E. Cristofori, B. Gozzini, M. Marchisio, J. Padoan, Analysis of the thermal comfort in cycling athletes, Procedia Engineering 34(0) (2012) 433-438.

[47] G.M. Revel, M. Arnesano, Perception of the thermal environment in sports facilities through subjective approach, Building and Environment 77(0) (2014) 12-19.

[48] N.H. Wong, S.S. Khoo, Thermal comfort in classrooms in the tropics, Energy and Buildings 35(4) (2003) 337-351.

[49] Y. Zhai, C. Elsworth, E. Arens, H. Zhang, Y. Zhang, L. Zhao, Using air movement for comfort during moderate exercise, Building and Environment 94 (2015) 344-352.

[50] Y. Zhang, R. Zhao, Overall thermal sensation, acceptability and comfort, Building and Environment 43(1) (2008) 44-50.

[51] M. Arnesano, Design of a comfort-based smart metering system for sport and recreational buildings, Doctoral school of engineering sciences, Università Politecnica delle Marche, 2013.

[52] M. Lebon, H. Fellouah, N. Galanis, A. Limane, N. Guerfala, Numerical analysis and field measurements of the airflow patterns and thermal comfort in an indoor swimming pool: a case study, Energy Efficiency 10(3) (2017) 527-548.

[53] P. Rajagopalan, M.B. Luther, Thermal and ventilation performance of a naturally ventilated sports hall within an aquatic centre, Energy \& Buildings 58 (2013) 122.

[54] P. Rajagopalan, E. Jamei, Thermal comfort of multiple user groups in indoor aquatic centres, Energy \& Buildings 105 (2015) 129-138.

[55] G.M. Revel, M. Arnesano, Measuring overall thermal comfort to balance energy use in sports facilities, Measurement 55(0) (2014) 382-393.

[56] SportE², D1.1 Performance criteria and requirements, Public access report, FP7, Online, 2012.

[57] D. Zangani, SportE ${ }^{2}$ Final Report: Intelligent Management System to Integrate and control energy generation, consumption and exchange for European Sport and Recreation Buildings, European FP7 Project, 2014.

[58] T. Al-hababi, E.E. Khalil, Numerical investigations of flow patterns and thermal comfort in airconditioned gymnastic sport facility, AIAA SciTech, San Diego, California, USA, 2016.

[59] P. Koper, B. Lipska, W. Michnol, Assessment of thermal comfort in an indoor swimming-pool, Architecture Civil Engineering Environment 3 (2010) 10.

[60] S. Tsoka, Optimizing Indoor Climate Conditions in a Sports Building Located in Continental Europe, Energy Procedia 78 (2015) 2802-2807.

[61] P. Sun, J.Y. Wu, R.Z. Wang, Y.X. Xu, Analysis of indoor environmental conditions and heat pump energy supply systems in indoor swimming pools, Energy and Buildings 43(5) (2011) 1071-1080.

[62] B. Yuce, H. Li, Y. Rezgui, I. Petri, B. Jayan, C. Yang, Utilizing artificial neural network to predict energy consumption and thermal comfort level: An indoor swimming pool case study, Energy and Buildings 80 (2014) 45-56.

[63] S. Gao, Y. Zhai, L. Yang, H. Zhang, Y. Gao, Preferred temperature with standing and treadmill workstations, Building and Environment 138 (2018) 63-73.

[64] H. Wang, S. Hu, Experimental study on thermal sensation of people in moderate activities, Building and Environment 100 (2016) 127-134.

[65] T. Kisilewicz, A. Dudzińska, Summer overheating of a passive sports hall building, Archives of Civil and Mechanical Engineering (0) (2015).

[66] F. Fantozzi, G. Lamberti, Determination of Thermal Comfort in Indoor Sport Facilities Located in Moderate Environments: An Overview, Atmosphere 10(12) (2019) 769.

[67] M. Jetté, K. Sidney, G. Blümchen, Metabolic equivalents (METS) in exercise testing, exercise prescription, and evaluation of functional capacity, Clinical Cardiology 13(8) (1990) 555-565.

[68] BSI, BS EN ISO 7726: 2001 Ergonomics of the thermal environment Instruments for Measuring Physical Quantities, British Standards Institution, London, UK, 2001.

[69] M.J. Fletcher, D.K. Johnston, D.W. Glew, J.M. Parker, An empirical evaluation of temporal overheating in an assisted living Passivhaus dwelling in the UK, Building and Environment 121 (2017) 106-118. 
[70] F.R.d.A. Alfano, B.I. Palella, G. Riccio, The role of measurement accuracy on the thermal environment assessment by means of PMV index, Building and Environment 46(7) (2011) 1361-1369. [71] BSI, BS EN ISO 9920:2009- Ergonomics of the thermal environment - Estimation of thermal insulation and water vapour resistance of a clothing ensemble (ISO 9920:2009) (Vol. 3), British Standards Institution, London, UK, 2010.

[72] BSI, BS EN ISO 8996:2004 Ergonomics of the thermal environment - Determination of metabolic rate, British Standards Institution, London, UK, 2005.

[73] M.H. Hasan, F. Alsaleem, M. Rafaie, Sensitivity study for the PMV thermal comfort model and the use of wearable devices biometric data for metabolic rate estimation, Building and Environment 110 (2016) 173-183.

[74] S.M. Gauthier, D. Shipworth, Predictive thermal comfort model: Are current field studies measuring the most influential variables?, 7th Windsor Conference: The Changing Context of Comfort in an Unpredictable World, 12-15 April 2012, Network for Comfort and Energy Use in Buildings, Cumberland Lodge, Windsor, UK, 2012.

[75] B. Koelblen, A. Psikuta, A. Bogdan, S. Annaheim, R.M. Rossi, Thermal sensation models: Validation and sensitivity towards thermo-physiological parameters, Building and Environment 130 (2018) 200-211.

[76] G. Havenith, I. Holmer, K. Parsons, Personal factors in thermal comfort assessment: clothing properties and metabolic heat production, Energy and Buildings 34(6) (2002) 591.

[77] G.M. Revel, M. Arnesano, F. Pietroni, Integration of Real-Time Metabolic Rate Measurement in a Low-Cost Tool for the Thermal Comfort Monitoring in AAL Environments, in: B. Andò, P. Siciliano, V. Marletta, A. Monteriù (Eds.), Ambient Assisted Living. Biosystems \& Biorobotics, Springer2015, pp. 101-110.

[78] S.I.-u.-H. Gilani, M.H. Khan, M. Ali, Revisiting Fanger's thermal comfort model using mean blood pressure as a bio-marker: An experimental investigation, Applied Thermal Engineering 109 (2016) 35-43.

[79] M. Luo, Z. Wang, K. Ke, B. Cao, Y. Zhai, X. Zhou, Human metabolic rate and thermal comfort in buildings: The problem and challenge, Building and Environment 131 (2018) 44-52.

[80] B.E. Ainsworth, W.L. Haskell, S.D. Herrmann, N. Meckes, D.R. Bassett Jr, C. Tudor-Locke, J.L. Greer, J. Vezina, M.C. Whitt-Glover, A.S. Leon, 2011 Compendium of Physical Activities: A Second Update of Codes and MET Values, Medicine \& Science in Sports \& Exercise 43(8) (2011) 1575-1581. [81] B.E. Ainsworth, W.L. Haskell, A.S. Leon, D.R. Jacobs, H.J. Montoye, J.F. Sallis, R.S. Paffenbarger, Compendium of Physical Activities: classification of energy costs of human physical activities, Medicine \& Science in Sports \& Exercise 25(1) (1993) 71-80.

[82] A. Ugursal, C.H. Culp, An Empirical Thermal Comfort Model for Transient Metabolic Conditions, ASHRAE Transactions 118(1) (2012) 10.

[83] T. Goto, J. Toftum, R. de Dear, P.O. Fanger, Thermal sensation and thermophysiological responses to metabolic step-changes, International Journal of Biometeorology 50(5) (2006) 323-32. [84] G. Havenith, H.O. Nilsson, Correction of clothing insulation for movement and wind effects, a meta-analysis, European journal of applied physiology 92(6) (2004) 636-40.

[85] Sport England, Active Places Power, Sport England, Online, 2019.

[86] Google, Aerial view of "Hall 1", Leeds Beckett University, Headingley Campus, 2019. https://www.google.co.uk/maps/@53.8270056,-

1.5933977,223a, 35y, 341.06h,32.12t/data $=! 3 \mathrm{~m} 1 ! 1 \mathrm{e} 3$ ?hl=en.

[87] A. Carre, T. Williamson, Design and validation of a low cost indoor environment quality data logger, Energy and Buildings 158 (2018) 1751-1761.

[88] O. Guerra-Santin, C.A. Tweed, In-use monitoring of buildings: An overview of data collection methods, Energy and Buildings 93 (2015) 189-207.

[89] M. Žitnik, K. Bučar, B. Hiti, Ž. Barba, Z. Rupnik, A. Založnik, E. Žitnik, L. Rodrìguez, I. Mihevc, J. Žibert, Exercise-induced effects on a gym atmosphere, Indoor Air 26(3) (2016) 468-477. 
[90] BSI, BS EN ISO 10551: 2001 Ergonomics of the thermal environment - Assessment of the influence of the thermal environment using subjective judgement scales, British Standards Institution, London, UK, 2002.

[91] CIBSE, CIBSE TM52: 2013 The limits of thermal comfort: avoiding overheating in European buildings, The Chartered Institution of Building Services Engineers, London, 2013.

[92] J. Fan, H.W.K. Tsang, Effect of Clothing Thermal Properties on the Thermal Comfort Sensation During Active Sports, Textile Research Journal 78(2) (2008) 111-118.

[93] J. Zuo, E. McCullough, Heat Transfer Characteristics of Sports Apparel, ASTM International 1(10) (2004).

[94] Y. Lu, F. Wang, X. Wan, G. Song, W. Shi, C. Zhang, Clothing resultant thermal insulation determined on a movable thermal manikin. Part I: effects of wind and body movement on total insulation, International Journal of Biometeorology 59(10) (2015) 1475-1486.

[95] S. Gibson, A. Numa, The importance of metabolic rate and the folly of body surface area calculations, Anaesthesia 58(1) (2003) 50-5. 